\title{
The opercular-subopercular syndrome: four cases with review of the literature
}

\author{
M. Bakar ${ }^{\mathrm{a}}$, H.S. Kirshner ${ }^{\mathrm{b}, *}$ and F. Niaz ${ }^{\mathrm{b}}$ \\ ${ }^{a}$ Department of Neurology, Uludag University, Bursa, \\ Turkey \\ ${ }^{\mathrm{b}}$ Department of Neurology, Vanderbilt University \\ School of Medicine, Nashville, TN 37232, USA.
}

\begin{abstract}
We present four cases of the 'opercular syndrome' of volitional paresis of the facial, lingual, and laryngeal muscles (bilateral facioglosso-pharyngo-masticatory paresis). Case histories and CT brain images are presented, along with a review of the literature concerning this long-recognized but little-known syndrome. The neuroanatomic basis of the syndrome classically involves bilateral lesions of the frontal operculum. We propose, on the basis of our cases and others, that the identical syndrome can arise from lesions of the corticobulbar tracts, not involving the cortical operculum. Our cases included one with bilateral subcortical lesions, one with a unilateral left opercular lesion and a possible, non-visualized right hemisphere lesion, one with unilateral cortical and unilateral subcortical pathology, and one with bilateral cortical lesions. These lesion localizations suggest that any combination of cortical or subcortical lesions of the operculum or its connections on both sides of the brain can produce a syndrome indistinguishable from the classical opercular syndrome. We propose the new term 'opercularsubopercular syndrome' to encompass cases with predominantly or partially subcortical lesions.
\end{abstract}

\section{Introduction}

The 'opercular syndrome', first described by Magnus in 1837, is also known as Foix-Chavany-Marie syndrome, after French authors who reported the syndrome in 1926 [3, 7], and also as facio-labio-pharyngoglosso-laryngo-brachial paralysis or the cortical type of pseudobulbar paralysis [18]. The opercular syndrome is characterized by a loss of voluntary control of facial, lingual, pharyngeal and masticatory muscles,

${ }^{*}$ Corresponding author: Howard S. Kirshner, Professor and Vice Chair, Department of Neurology, Vanderbilt Medical Centre South \#362, 2100 Pierce Avenue, Nashville, TN 37212, USA.

Behavioural Neurology 11 (1998) 97-103

ISSN 0953-4180 / \$8.00 (C) 1998, IOS Press. All rights reserved in the presence of preserved reflexive and automatic functions of the same muscles [15, 20]. For example, the typical patient may be unable to open and close the mouth voluntarily, yet the mouth opens automatically during yawning. Most patients cannot blink their eyes, smile, open the mouth, protrude the tongue, speak, or swallow voluntarily.

The neuroanatomical basis of the opercular syndrome usually involves bilateral abnormality of the opercular cortex, as in the classical cases [2, 3, 15, 17] Modern authors have used the term 'opercular syndrome' to apply to the same clinical syndrome of bilateral corticobulbar involvement with facio-labiopharyngo-glosso-laryngo-brachial paralysis, with dissociation between automatic and volitional movement of these muscles, whether the responsible lesions are cortical or subcortical $[18,20]$. Most cases of the syndrome have had lesions of the anterior (frontal) part of the operculum; some authors have referred to the syndrome as the 'anterior opercular syndrome [15].' Bilateral lesions of the posterior middle cerebral artery territory can cause pure word deafness without the ocular, facial, and laryngeal difficulties seen in the anterior opercular syndrome. Finally, a few cases of 'unilateral opercular syndrome' have been reported $[18,20]$. An anterior unilateral opercular syndrome involves muteness and contralateral, supranuclear cranial nerve abnormalities [18]; a posterior, 'cheiro-oral' opercular syndrome has also been described, in which sensory loss involves the contralateral face and hand [2]. Neither of these unilateral opercular syndromes involves the bilateral cranial nerve findings seen in the bilateral, anterior opercular syndrome [2]. Even more rarely, cases have been reported in which bilateral cranial nerve abnormalities and automato-volitional dissociation have occurred with an apparently unilateral lesion [20]. We report four new cases of the opercular syndrome. 


\section{Report of cases}

Patient 1: This 48 year-old right handed male was admitted for the sudden onset of inability to speak or swallow. Five years earlier he had experienced a first stroke, leaving him with residual left hemiparesis. There was no history of hypertension, heart disease, diabetes, or smoking. On examination, he was alert and oriented, as judged by his response to multiple choice questions, but he was completely mute. His extraocular movements were normal, but there was bilateral dysfunction noted on examination of the 5th, 7th, 9th, 10th, and 12th cranial nerves. He was unable to close his eyes, open his mouth, chew, or swallow on request. His tongue was immobile in his mouth. The blink reflex, as well as reflexive swallowing to gag testing, and even spontaneous smiling were all preserved, though he could not smile to command. By contrast, he promptly followed commands to move his right limbs, indicating preserved language comprehension and limb praxis. He had a moderate left spastic hemiparesis residual from his first stroke and very slight right hemiparesis, new since the second stroke. Plantar responses were extensor bilaterally, and he had left ankle clonus. Sensory examination was normal to pinprick, touch and vibration. Gait was hemiparetic, with circumduction of the left leg. He had marked difficulty eating, with limited chewing, tongue movements, and swallowing. On bedside mental status examination, he was mute and aphonic. Comprehension of auditory and written commands and questions was intact, and he could write normally, both spontaneously and to dictation. Written calculations were accurate. He appeared emotionally appropriate and aware of his situation. CT scan showed a large hypodense area in the right putamen and a small hypodense area in the left periventricular region (Fig. 1). A summary of clinical and CT scan features of all four patients is presented in Table 1.

Patient 2: This 39 year-old right handed black female had no history of medical problems except for a 20 pack-year smoking history. She was entirely well until four years earlier, when she developed the sudden onset of right side weakness, mild speech difficulty, and mild dysphagia, all of which resolved completely. In 1983 she was admitted for a second stroke which rendered her unable to speak or swallow. On neurologic examination she was alert but mute. She had normal pupillary light reflexes and full extraocular movements. She could not open her mouth or make any facial gestures to command. Her mouth opened only when she yawned or cried. She could not protrude her tongue or swallow on command. She had no extremity weakness except for minimal difficulty with fine finger movements in the left hand. Sensory and cerebellar examinations were normal. On mental status examination, she was anarthric, but her auditory and reading comprehension were normal, and she communicated well by writing sentence-length material with her right hand. She had normal memory for three items, tested by having her write the responses, and she could also perform calculations accurately in written form. Cerebral arteriography showed a paucity of vessels in both the right and left middle cerebral artery distributions, with normal extracranial carotid vessels. Residual effects of embolization were suspected. Videofluoroscopy of swallowing in the lateral plane revealed total absence of the volutional oral stage of swallowing; the study was not carried further. CT scans on admission and 18 days later (Fig. 2) showed only a single area of infarction in the left frontal operculum and insula. During the ensuing twelve years, she has remained completely mute except for moaning or laughing sounds, but she has maintained normal understanding and intelligence. She communicates by writing and by computer keyboard and is fully ambulatory. She eventually returned to work as a librarian, working largely on the library computer system. She took herself to work and back each day on a public bus while still unable to speak. No other 'frontal' or language deficits have been apparent during long-term follow-up. She had a feeding tube for a few months after the second stroke, then discovered on her own that she could drink beverages and swallow solids once these were introduced into the posterior oral cavity. She discontinued her own nasogastric tube and has never shown evidence of dehydration, malnutrition, or aspiration pneumonia.

Patient 3: This 66 year old man with chronic hypertension was admitted for the abrupt onset of left-sided weakness and difficulty speaking. He had reportedly suffered at least two prior strokes, with only slurred speech and unsteady gait as residual deficits. He reportedly stood up from the commode and fell because of left-sided weakness; he was incontinent of urine, lethargic, and unable to speak at the time of arrival in a local hospital. On arrival at the Nashville VA Medical Center he was able to speak hesitantly, name common objects, repeat phrases, and follow simple commands, spoken or printed. There was no apparent difficulty in processing auditory language inputs, and no 'frontal' deficits were apparent on bedside exami- 


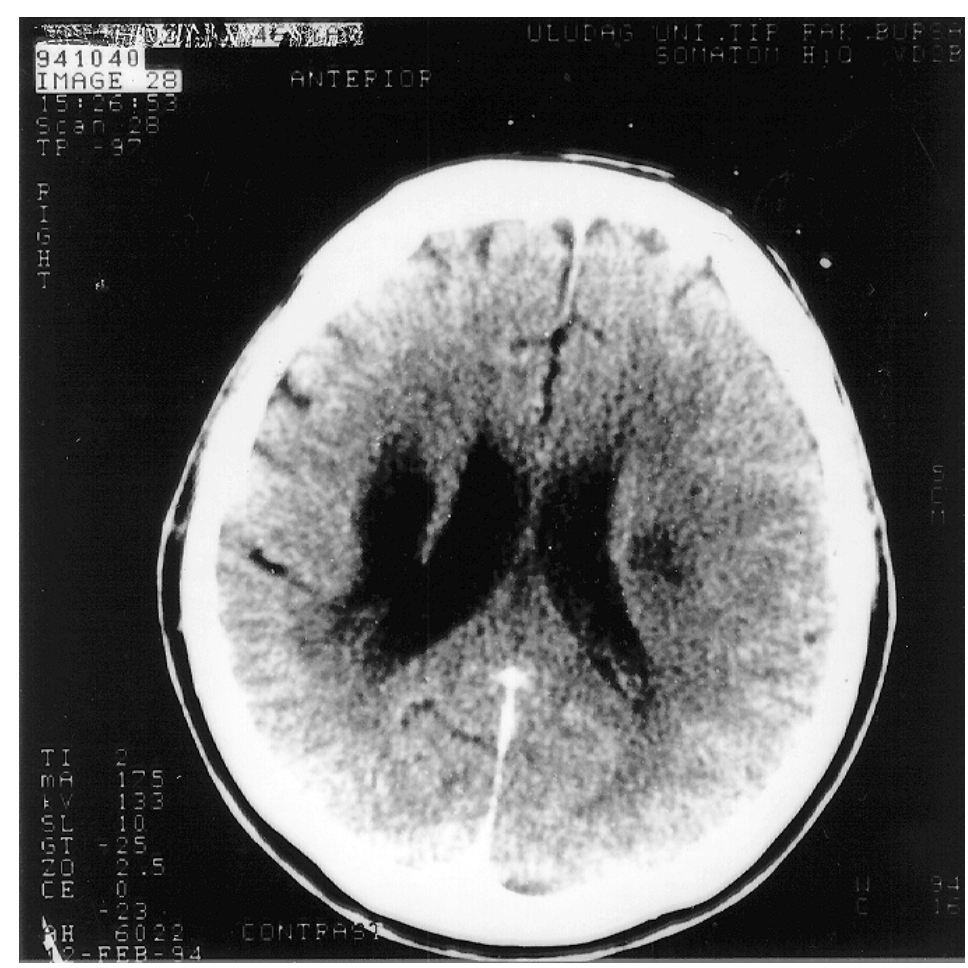

Fig. 1. CT scan cuts from Patient 1, showing a large hypodense area in the right putamen and overlying corona radiata, as well as a smaller area of infarction in the left periventricular area.

Table 1

Clinical and CT scan features of 4 cases

\begin{tabular}{|c|c|c|c|c|}
\hline & Patient 1 & Patient 2 & Patient 3 & Patient 4 \\
\hline Age, gender & 48 , male & 39 , female & 66 , male & 62 , male \\
\hline Prior stroke & L hemiparesis & $\begin{array}{l}\mathrm{R} \text { hemiparesis, } \\
\text { resolved }\end{array}$ & $\begin{array}{l}\text { Multiple strokes, } \\
\text { dysarthria, gait } \\
\text { imbalance }\end{array}$ & $\begin{array}{l}2 \text { strokes } \\
\text { L hemiparesis }\end{array}$ \\
\hline New stroke & $\begin{array}{l}\text { Mild R } \\
\text { hemiparesis }\end{array}$ & $\begin{array}{l}\text { Minimal R } \\
\text { hemiparesis }\end{array}$ & $\mathrm{L}$ hemiparesis & $\mathrm{R}$ hemiparesis \\
\hline CT Findings & $\begin{array}{l}\mathrm{R} \text { putamen, } \\
\mathrm{L} \text { periventricular } \\
\text { infarcts }\end{array}$ & $\begin{array}{l}\text { L frontal } \\
\text { operculum, } \\
\text { insula only }\end{array}$ & $\begin{array}{l}\text { Bilateral } \\
\text { caudate/ant } \\
\text { limb/putamen, } \\
\text { new R frontal }\end{array}$ & $\begin{array}{l}\text { Bilateral } \\
\text { opercular } \\
\text { infarctions }\end{array}$ \\
\hline
\end{tabular}

nation. He wrote his name and a few phrases to dictation. The neurological examination was otherwise remarkable only for left arm and leg weakness $(4 / 5$ left arm, 3/5 left leg) and a probable left upgoing toe; cranial nerve and sensory examinations were normal. On the following morning, the patient was completely mute, with a dense left hemiplegia. He followed only very simple commands, was unable to move his face or mouth, eat, or swallow. He did smile reflexively, yawn, and swallow when tested for the gag reflex. He had normal strength on the right side. CT scan on the day of admission showed a $1.5 \mathrm{~cm}$ diameter infarct in the right head of caudate and anterior limb of internal capsule and a slightly larger lesion in the left head of caudate, anterior limb, and anterior putamen. A follow-up CT scan four days later (Fig. 3) showed a new, larger lesion in the right medial frontal lobe, anterior to the caudate nucleus, extending medially to the falx and anteriorly towards the frontal pole.

In the course of a two-month hospitalization, this patient's opercular syndrome gradually, improved. He regained very limited oral expression. He gradually 

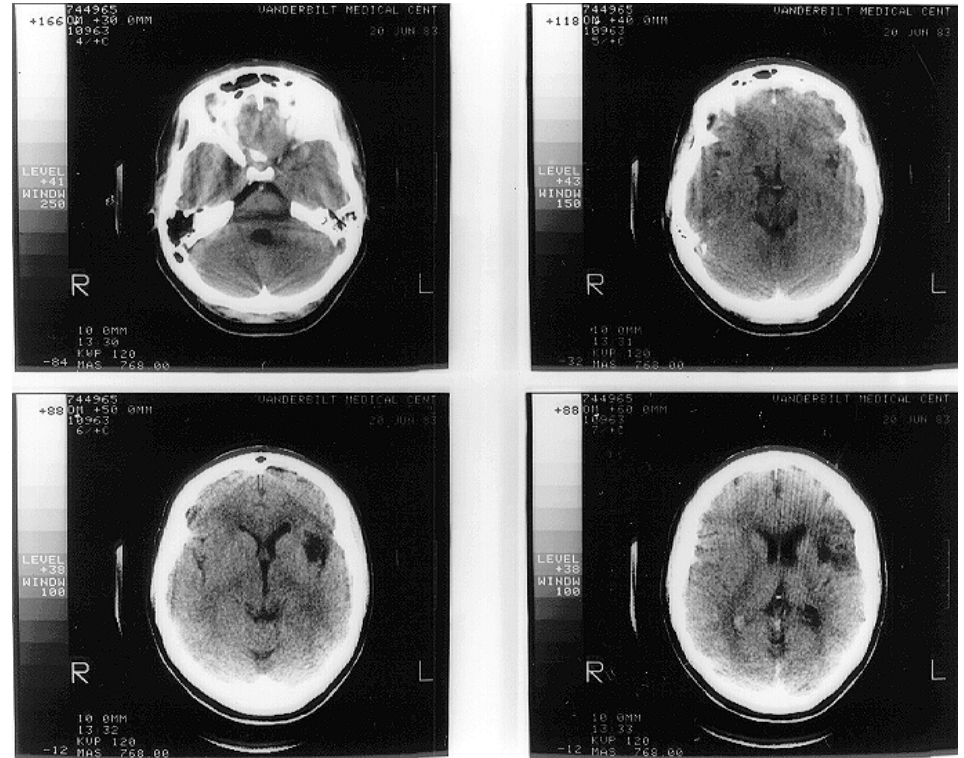

Fig. 2. CT scan cuts from Patient 2 (18 days post-onset), showing only a left frontal, cortical and subcortical opercular and insular infarction.

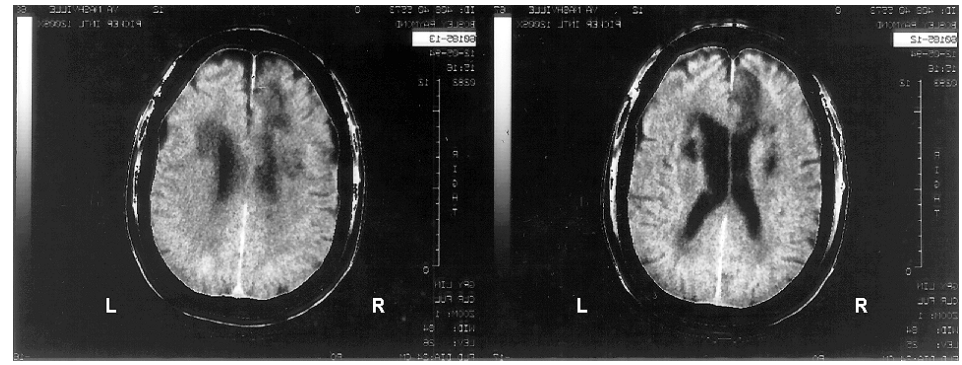

Fig. 3. CT scan, Patient 3, four days after admission, showing a right subcortical lesion involving the head of the caudate and anterior limb of internal capsule, a left subcortical lesion involving the head of the caudate, anterior limb, and anterior putamen, and a new lesion of the right medial frontal lobe. Note that right and left are reversed from the usual convention on this photograph, and the right side of the picture corresponds to the right side of the brain.

became able to swallow a dysphagia diet, but he remained unable to smile, move his face, or protrude his tongue to command. He was noted to yawn spontaneously, however, and his facial muscles moved also during mastication of his food. The patient was tested on two occasions, shortly after admission and six weeks later, with the Boston Assessment of Severe Aphasia (BASA, [10]). As shown in Table 2, he improved moderately in auditory comprehension, more so in reading comprehension and praxis. After therapy by speech pathologists with Visual Action Therapy (VAT, [11]), his auditory comprehension improved from the 71 st to the 93rd percentile on onestep commands and from the 57th to the 71st percentile on yes/no questions. His reading comprehension improved from the 84th to the 99th percentile as judged by single word reading and from the 83 rd to
Table 2

Boston assessment of severe aphasia, case 3

\begin{tabular}{|c|c|c|}
\hline Measure & Percentile & Percentile \\
\hline & Week 2 & Week 9 \\
\hline Auditory comprehension & 5 & 37 \\
\hline Praxis & 2 & 75 \\
\hline Oral-gestural expression & 9 & 25 \\
\hline Reading comprehension & 25 & 91 \\
\hline Other items ${ }^{a}$ & 9 & 16 \\
\hline BASA total & 5 & 30 \\
\hline
\end{tabular}

${ }^{a}$ Other items: gesture recognition, writing signature, visuo-spatial tasks (draw a man, match designs, memory for designs).

the 85 th percentile when tested with two-step printed commands.

Patient 4: This 62 year old right-handed male was admitted for the sudden onset of inability to walk, speak, or swallow. The patient had a history of two 


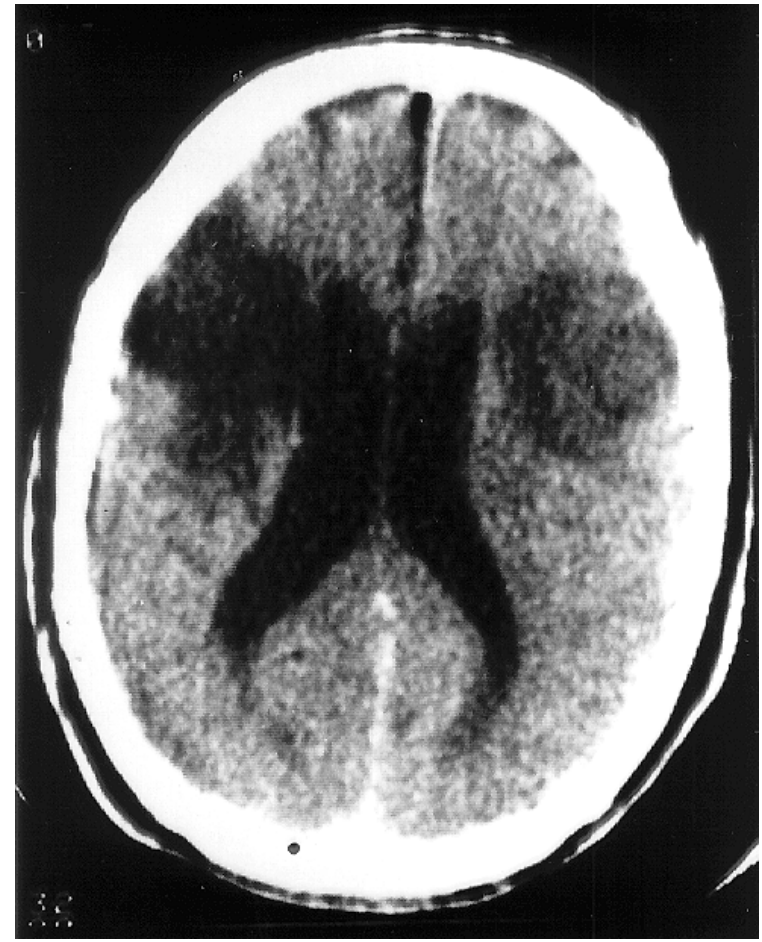

Fig. 4. CT scan, Patient 4. The scan shows bilateral corticalsubcortical infarctions involving the operculum, larger right than left.

strokes, two years and five months previously, both associated with left-sided weakness, leaving him with a mild spastic left hemiparesis. The past medical history was positive for coronary artery disease, status post three myocardial infarctions, but negative for hypertension or diabetes. He was a 90 pack-year smoker. On examination, he was alert and followed commands well, but he could not speak. He was unable to write and did not cooperate with attempts to test calculations or memory in written form. Cranial nerve examination disclosed supranuclear paresis of cranial nerves V, VII, IX, and XII. He could not close his eyes, open his mouth, chew, move his tongue, or swallow to command, yet he blinked and yawned spontaneously. On motor examination, there was mild, residual left hemiparesis and a more severe right hemiparesis. Reflexes were hyperactive bilaterally, with a right upgoing toe. CT scan (Fig. 4) showed a bilateral infarctions in the middle cerebral artery territory.

\section{Discussion}

Since the original case report of the opercular syndrome presented by Magnus in 1837, only about 30 additional patients have been described, mainly by French authors [3, 7]. Anatomically, the term 'operculum' refers to the cortices which surround the insula, including the inferior frontal, pre-and postcentral, supramarginal and angular (inferior parietal), and superior temporal convolutions, with variable involvement of the subjacent white matter [3]. Voluntary control of face, tongue and pharynx movement requires intact primary motor cortices and pyramidal pathways; spontaneous, emotional control of the same muscles, on the other hand, requires intact extrapyramidal pathways and probably portions of the thalamus and hypothalamus [4]. Lesions involving the motor cortices, subcortical areas, or pyramidal pathways bilaterally produce a selective palsy of voluntary use of the facial, pharyngeal, and masticatory muscles $[4,15]$. This selective volitional palsy of facial muscles in patients with bilateral anterior opercular lesions is referred to as an 'automato-voluntary dissociation' [15]. The opercular syndrome displays the clinical manifestations of pseudobulbar paralysis in the distribution of the 5th, 7th, 9th, 10th, 12th cranial nerves [3, 17, 22]. As stated earlier, the identical syndrome can also occur in the presence of lesions sparing the operculum but involving its corticobulbar projections in the internal capsule or brainstem $[18,20]$. The alternate term 'opercular-subopercular syndrome' is proposed.

Etiologically, the great majority of instances of the syndrome are multiple strokes, either thrombotic or embolic [15]. Encephalitis, trauma, tumors, developmental perisylvian dysplasia, vasculitis, and degenerative disease are less common causes of this syndrome $[3,6,7,9,14,15,16,17,19,21,23]$. Recently, the opercular syndrome has been reported with bilateral toxoplasmosis lesions in a patient with AIDS; the authors point out that the frequent occurrence of multiple lesions in AIDS patients may make this a common finding [8]. Our first case had two types of cerebrovascular event, the first a right putamenal hemorrhage, the second a small, left periventricular infarction. The second patient had a left frontal infarct and, by clinical indications, a second infarction on the right side, not visualized by $\mathrm{CT}$. We prefer this explanation to the postulation of a strictly unilateral cause of the opercular syndrome, especially since the syndrome followed a new event with subtle left hand weakness. Cases of unilateral 'opercular syndrome,' however, have been reported $[18,20]$. The third patient had a new right medial frontal infarction, with prior bilateral infarctions involving the caudate head and anterior limb. The fourth patient had bilateral cortical-subcortical lesions 
involving the middle cerebral artery territory. Interestingly, this is the only case in our series with the classical finding of bilateral, cortical opercular lesions. Our cases all had CT scans, since this was the only modality available at the time of presentation in Case 2, and because MRI scans were not routinely available in Bursa, Turkey or at the Nashville VA Medical Center when Cases 1, 3, and 4 presented. MRI may reveal additional lesions as compared to $\mathrm{CT}$ in patients with opercular syndrome secondary to stroke, and we suspect that an additional, contralateral lesion might have been detected by MRI in Case 2 .

The opercular syndrome must be distinguished from catatonia, akinetic mutism, oral buccal apraxia, Broca's aphasia, pseudobulbar palsy, and bulbar palsy secondary to myasthenia gravis, Guillain-Barré syndrome, and brainstem strokes. The prompt ability of the patient to follow commands involving limb muscles differentiates the patient with the opercular syndrome from those with catatonia or akinetic mutism. Broca's aphasia, even when associated with muteness, does not involve the total loss of voluntary movement in the cranial musculature. The opercular syndrome can be considered a form of pseudobulbar palsy, in terms of the muteness and aphagia, and often increased jaw and gag reflexes. The involuntary laughter and crying which are often a part of pseudobulbar palsy are not seen in all cases of either the opercular syndrome or pseudobulbar palsy. The only real difference between the opercular syndrome and pseudobulbar palsy is that the opercular syndrome implies a complete syndrome of muteness and inability to move the facial, buccal, lingual and pharyngeal muscles, while pseudobulbar palsy includes more partial bipyramidal syndromes with dysarthria. Buccal or buccofacial apraxia refers to the inability to follow commands related to the oral apparatus, while these muscles can be used spontaneously. The automato-voluntary dissociation thus applies both to the opercular syndrome and buccal apraxia. Buccal apraxia clearly can be a part of the opercular syndrome, though most patients with buccal apraxia are not completely mute [5], nor in most cases are they completely unable to move the facial, lingual, and pharyngeal muscles. Speech apraxia, also called verbal apraxia, refers to syndromes of errors in the production of multisyllabic utterances, usually associated with single, left hemisphere lesions [12, 13]; such a deficit cannot even be tested in a mute patient. The opercular syndrome differs from bulbar palsy by the lack of fasciculations, atrophy, and absent jaw and gag reflexes as would be expected in a lower motor neuron syndrome. Bulbar palsy secondary to the GuillainBarré syndrome and myasthenia gravis are also differentiated from the opercular syndrome by the lack of the automato-voluntary dissociation in eye and facial movements [15, 17, 22].

The opercular syndrome is classically ascribed to direct involvement of the opercular cerebral cortex. As described above, however, subcortical lesions can produce the syndrome by destroying fibers connecting cortical and subcortical structures and descending pyramidal pathways, in the absence of cortical damage $[18,23]$. A few cases of unilateral opercular syndrome secondary to a unilateral cortical lesion have been described [3], whereas only one case has been described of the opercular syndrome secondary to a unilateral subcortical stroke [18]; this patient did not have a complete, bilateral syndrome. To our knowledge, our first case is the first reported instance of the bilateral opercular syndrome secondary to bilateral subcortical strokes, though cases of pseudobulbar palsy have been reported with bilateral subcortical lesions [1]. The other, previously reported case of a bilateral subcortical opercular syndrome was associated with a progressive upper motor neuron degenerative syndrome, primary lateral sclerosis [23]. Another point worth emphasizing is the surprisingly small size of the lesion associated with the second stroke in our first two cases, in view of the devastating, bilateral cranial nerve syndromes which resulted. The second stroke, which produced no disabling weakness or sensory impairment in the limbs, resulted in severe, total, bilateral upper-motor-neuron involvement of the 5th, 7th, 9th, 10th, and 12th cranial nerves. It appears that the other hemisphere has a large capacity to compensate for a unilateral lesion, but a small lesion in the intact hemisphere can then bring out multiple pseudobulbar findings on both sides, not evident after the first stroke. Another possible explanation for the profound effects of the second, left hemisphere stroke in these patients would be a relative dominance of one hemisphere for these cranial nerves functions [17]. Usually, this dominant hemisphere is thought to be the left. The case of bilateral opercular syndrome secondary to a unilateral lesion reported by Starkstein et al. [20] had a lesion involving the right insula, with extension to the frontoparietal operculum; no left hemisphere lesion was evident at autopsy, approximately one month post-onset. The patient was beginning to speak at the time of death, so the permanence of the unilateral syndrome is uncertain. Nonetheless, this case provides the best evidence that a unilateral lesion can produce a bi- 
lateral opercular syndrome. We suspect that our Case 2 , as well as most other cases of the bilateral opercular syndrome secondary to a unilateral lesion, actually have a subtle lesion on the second side. The natural history of the opercular syndrome has not been studied in detail. Our second case has had a stable syndrome of near-muteness for twelve years. The response to speech therapy with Visual Action Therapy [10] is of interest, but the applicability of this therapy technique in cases of the opercular syndrome will require further study.

In conclusion, our cases and those cited from the literature suggest that the opercular syndrome can be produced by any combination of cortical or subcortical lesions affecting the corticobulbar pathways for the cranial nerves in both hemispheres. The term 'opercular-subopercular' syndrome' would take into account subcortical localizations for the syndrome.

\section{References}

[1] G. Besson, J. Bogousslavsky, F. Regli and P. Maeder, Acute pseudobulbar or supranuclear bulbar palsy, Arch. Neurol. 48 (1991), 501-507.

[2] J. Bogousslavsky, K. Dizerens and F. Regli, Despland P-A. Opercular cheiro-oral syndrome, Arch. Neurol. 48 (1991), 658-661.

[3] G.W. Bruyn and J.C. Gathier, The operculum syndrome, in: Handbook of clinical Neurology, Vol 2, P.J. Vinken, G.W. Bruyn, ed., Amsterdam: North Holland, 1969, pp. 776-783.

[4] R.N. Dejong, The neurologic examination, MD: Harper \& Row, 4th ed. Hagerstown, 1979, 190.

[5] E. DeRenzi, A. Pieczuro and L.A. Vignolo, Oral apraxia and aphasia, Cortex 2 (1966), 50-73.

[6] B. Duche and C. Marchal, P. Loiseau and C. Louvet Giendaj, Facio-Linguo-Masticatory diplegia and epilepsy. Cortical dysplasia, Rev. Neurol. 148(8-9) (1992), 562-565.

[7] N.R. Graff-Radford, E.P. Bosch, J.C. Stears and D. Tranel, Developmental Foix-Chavany-Marie syndrome in identical twins, Ann. Neurol. 20 (1986), 632-635.

[8] M.P. Grassi, M. Borella, F. Clerici, C. Perin, M.T. Bini and A. Mangoni, Reversible bilateral opercular syndrome secondary to AIDS-associated cerebral toxoplasmosis, Ital. J. Neurol. Sci. 15 (1994), 115-117.

[9] Z. Grosswasser, I. Grosswasser Reider and C. Korn, Biopercular lesions and acquired mutism in a young patient, Brain Inj. 5(3) (1991), 331-334.

[10] N.A. Helm-Estabrooks, P.M. Fitzpatrick and B. Barresi, Visual action therapy for global aphasia, J. Sp. Hearing Dis. 47 (1982), 385-389.

[11] N. Helm-Estabrooks, A.R. Ramsberger and M.N. Morgan, BASA: Boston assessment of severe aphasia, Special Press Inc., San Antonio, TX, 1989.

[12] D.F. Johns and F.L. Darley, Phonemic variability in apraxia of speech, J. Speech Hearing Res. 13 (1970), 556-583.

[13] H.S. Kirshner, Apraxia of speech: A linguistic enigma. A neurologist's perspective, Sem. Speech Lang. 13 (1992), 14 24.

[14] C. Lang, J. Rechwein, H. Iro and T. Treig, Foix-ChavanyMarie syndrome. Neurological, neuropsychological, CT, MRI, and SPECT findings in a case progressive for more than 10 years, Eur. Arch. Psychiatry 239(3) (1989), 188-193.

[15] C.C. Mao, B.M. Coull, L.C. Golper and M.T. Rau, Anterior opercular syndrome, Neurology 39 (1989), 1169-1172.

[16] G.C. Marchiori, G. Trincia and S. Cusumano, Labio-glossopharyngo laringealparalysis caused by two brain lesions: Cortical and subcortical, Ital. J. Neurol. Sci. 12(4) (1991), 419422.

[17] C. Mariani, H. Spinnler, R. Sterzi and G. Vallar, Bilateral perisylvian softenings: Bilateral anterior opercular syndrome (Foix-Chavany-Marie syndrome), J. Neurol. 223 (1980), 269-284.

[18] L. Posteraro, F. Pezzoni, E. Varalda, G. Fugazzo and A. Mazzucchi, A case of unilateral opercular syndrome associated with subcortical lesion, J. Neurol. 238 (1991), 337-339.

[19] M.I. Shevell, L. Carmont, K. Meagher Willemure, Developmental bilateral perisylvian dysplasia, Ped. Neurol. 8(4) (1992), 299-302.

[20] S.E. Starkstein, M. Berthier and R. Leiguarda, Bilateral opercular syndrome and crossed aphemia due to a right insular lesion: A clinicopathological study, Brain and Language 34 (1988), 253-261.

[21] J.C. Van der Poel, C.A. Haenggeli and W.C. OverwegPlandsoen, Operculum syndrome: unusual feature of herpes simplex encephalitis, Pediatr. Neurol. 12 (1995), 246-249.

[22] M. Weller, How to define the opercular syndrome? (letter), J. Neurol. 239(5) (1992), 294-95.

[23] M. Weller, M. Poremba and J. Dichgans, Opercular syndrome without opercular lesions: Foix-Chavany-Marie syndrome in progressive supranuclear motor system degeneration, Eur. Arch. Psychiatry Neurol. Sci. 239(6) (1990), 370-372. 


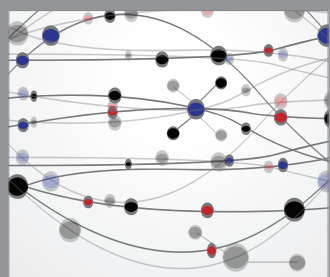

The Scientific World Journal
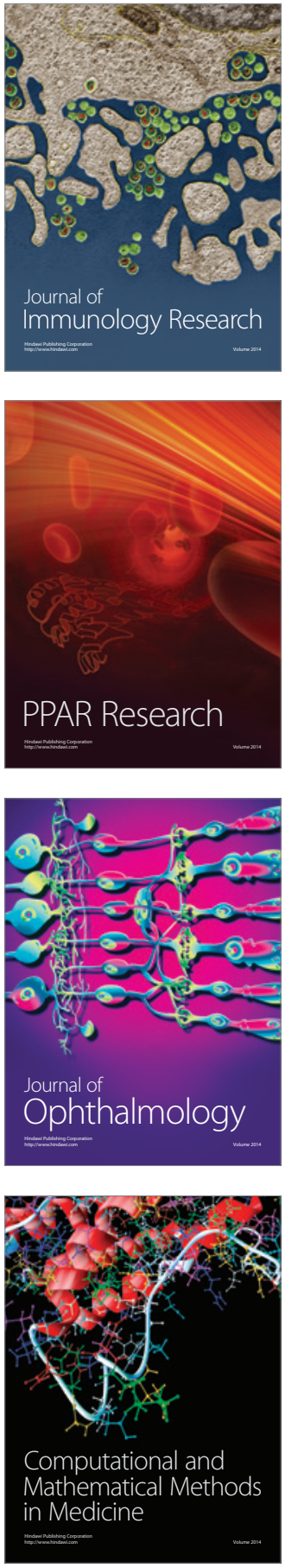

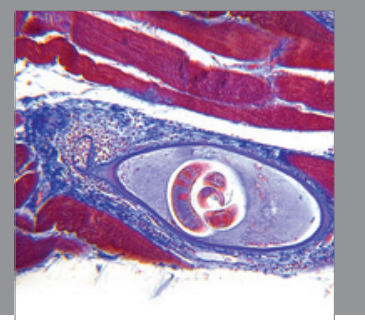

Gastroenterology

Research and Practice
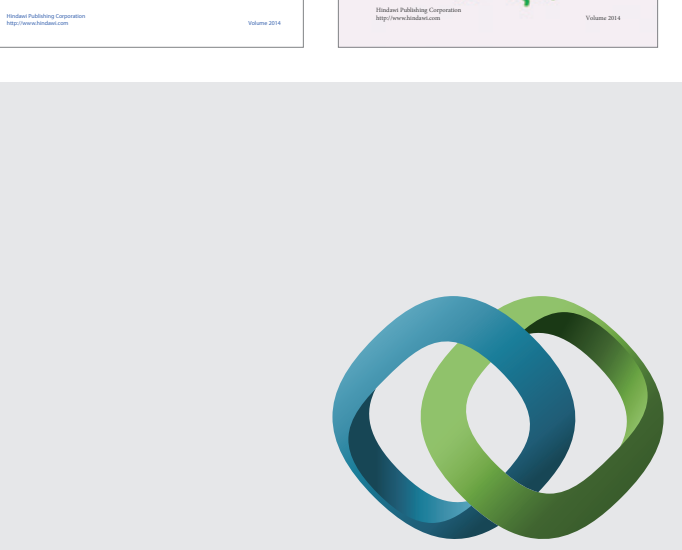

\section{Hindawi}

Submit your manuscripts at

http://www.hindawi.com
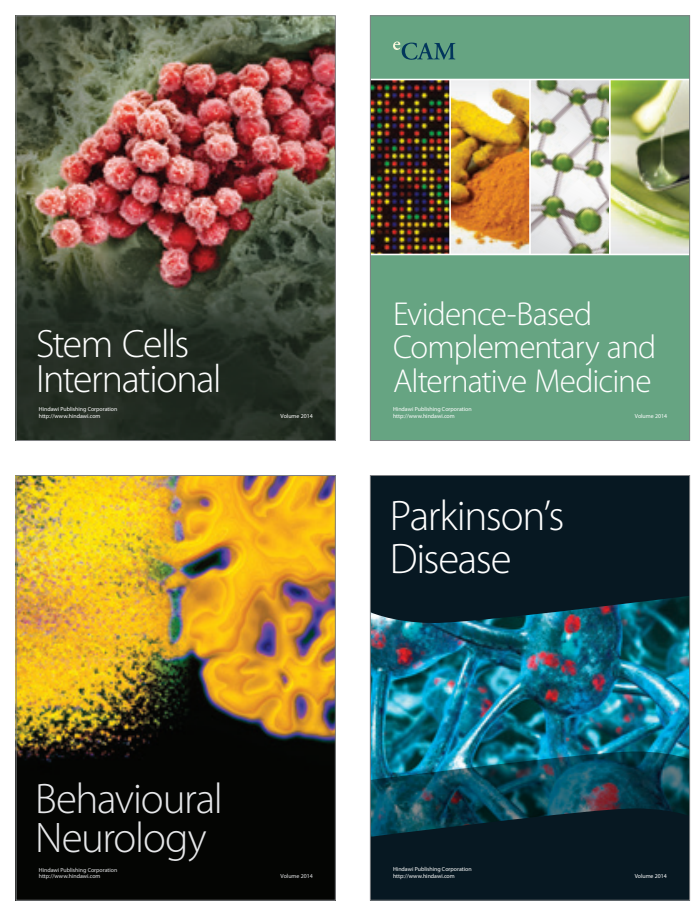

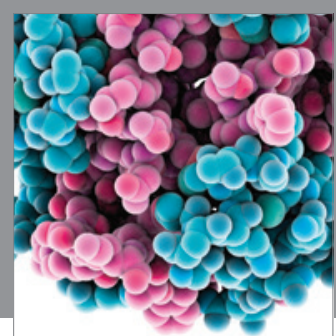

Journal of
Diabetes Research

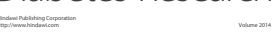

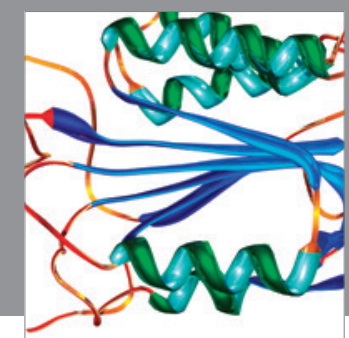

Disease Markers
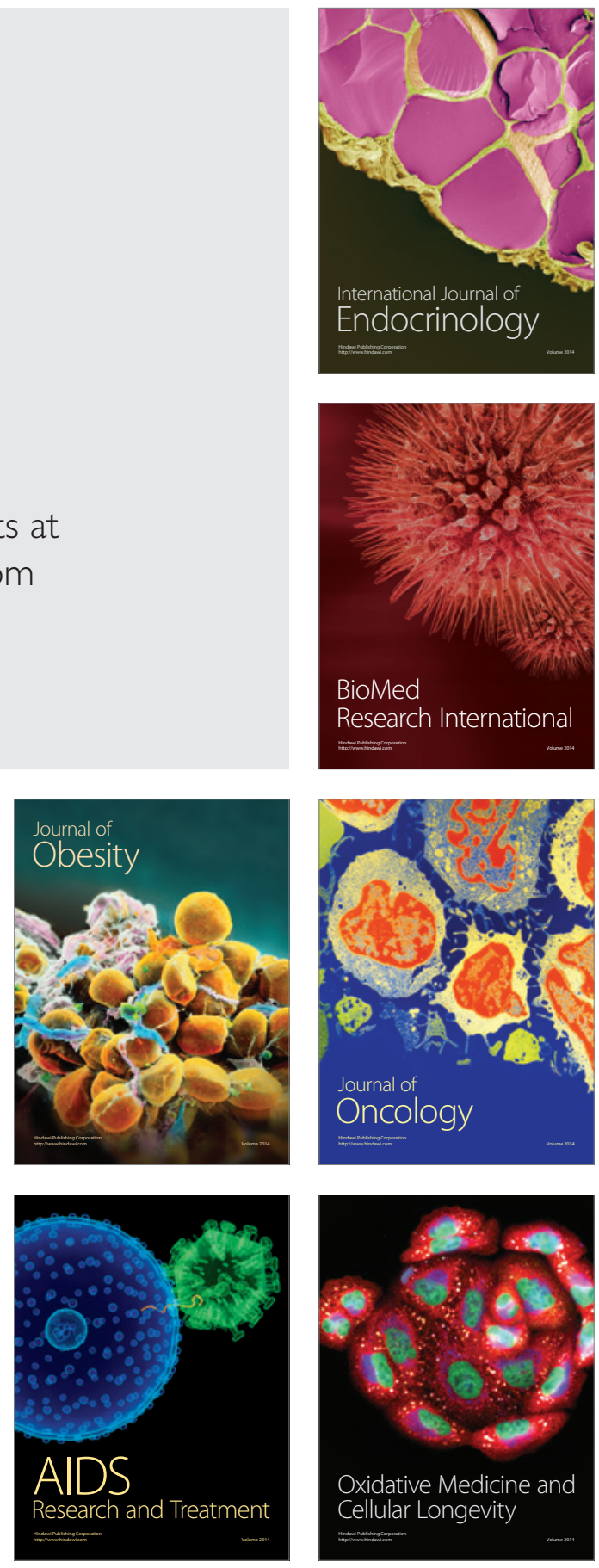